\title{
ESTUDO DAS FORMAS ANÓMALAS DA LEISHMANIOSE TEGUMENTAR
}

\author{
Domingos Silva
}

O A. apresenta um estudo das formas anômalas da leishmaniose tegumentar, detalhando particularmente a forma disseminada da doença, para a qual propóe a denominação de leishmaniose anérgica hansenóide.

A LEISHMANIOSE TEGUMENTAR causada pela Leishmania brasiliensis, é uma parasitose muito frequente no Brasil, onde apresenta alguns grandes focos. Destes, deve-se destacar nesta oportunidade, o foco amazônico, altamente ativo - particularmente nestes últimos anos pela abertura de novas vias de comunicação e a instalação de povoados, com a consequente derrubada de florestas.

Aqui, como em outras regiōes brasileiras, os aspectos clínicos da leishmaniose tegumentar não diferem fundamentalmente.

É clássico admitir-se que a Leishmaniose à Leishmania brasiliensis tem acentuada tendência ao ataque às mucosas, no que difere da forma oriental, determinada pela Leishmania tropica. Em 378 casos, etiològicamente comprovados, registrados no Departamento de Dermatologia do Centro BioMédico, da Universidade Federal do Pará (Serviço do Prof. Domingos Silva), a distribuição das formas clinicas foi a seguinte:

\section{LEISHMANIOSE TEGUMENTAR}

PARÁ

$1965-1970$

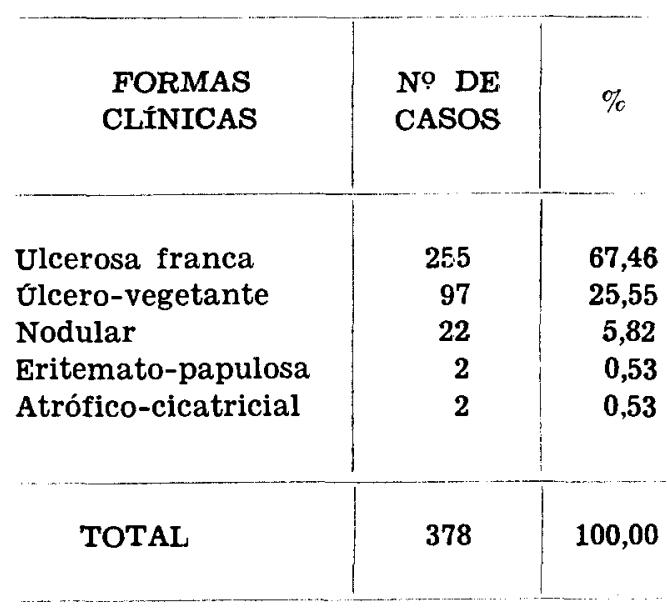

- Trabalho apresentado ao VII Congresso da Sociedade Brasileira de Medicina Tropical, Manaus, feverelro de 1971 .

* Professor Titular de Dermatologia, Departamento de Dermatologia - Centro Bio-Médico da Universidade Federal do Pará.

Recebido para publicaçăo em 5.2 .72 
Nesta apresentaçāo, entretanto, 1remos estudar apenas as formas anômalas, isto é, tipos clínicos que fogem dos aspectos usuais de leishmaniose tegumentar, confundindo-se com outras afecções tropicais, particularmente a "leishmaniosis cutis difusa" bem estudada por Convit et als. (7) na Venezuela e que preferimos chamar de "Leishmaniose anérgica hansenóide" por motivos que exporemos mais adiante.

\section{- FORMAS ANOMALAS DE}

\section{LEISHMANIOSE}

1) Lesões nodulares ou nodulares ulceradas - localizadas exclusivamente nas orelhas, apresentando aspecto clínico da "úlcera de los chicleros", comum no México e determinada pela Leihmania mexicana (fig. 1).

2) Lesões gomosas ulceradas - quando localizadas em certas éreas do corpo podem ser confundidas com actinomicose ou escrofuloderma (fig. 2 e 3 ).

3) Lesões ulcerosas - localizadas nos membros inferiores, próximo ao maléolo apresentando por vezes fenômeno de gravitação, abundante secreção, fétida, estando a úlcera recoberta de induto pardacento (fig. 4). Pode ser confundida com úlcera tropical, proparte, determinađa pela associação fusoespirilar.

4) Localização em áreas cobertas do corpo - tais como bolsa escrotal (fig. 5), registrada raramente no adulto, que pelo menos protegem as regiōes pudendas, pelo uso de calção. o caso que apresentamos num paciente com leishmaniose evoluindo há vários anos, relaciona-se com surtos periódicos de aparecimento de novas lesões, acreditando-se em disseminação hematogênica.

5) Leishmaniose anérgica hansenóide Também chamada leishmaniose tegumentar de forma disseminada, Convit \& Lapenta, 1948 (8); leishmaniose disseminada de aspecto lepromatoso, Mayer \& cols, 1949 (13); leishmaniose tegumentar queloidiana, - D. Silva, 1958 (24); leishmaniose lepromatosa, Pessoa, 1961 (19) etc.
Estas designaçōes sāo evidentemente impróprias por relacionar esta forma clínica aos qualificativos: "lepromatosa" "de aspecto lepromatoso" etc.

Ainda que até certo ponto justificáveis pelo fato das lesões apresentarem a mesma conotação semiótica da lepra lepromatosa, somos forçados a relembrar que há, em todo o mundo, um grande esforço no sentido de prescrever a palavra lepra e seus derivacios pelas sérias implicações sociais de todos conhecidas.

Assim sendo, nada justifica que se adicione à leishmaniose o verbete interdito. Não podemos negar, é bem verdade, que as lesões desta forma anômala de leishmaniose simulam de modo extraordinário o quadro clínico da hanseniase. Assim é que nossos 3 casos, dois (obs. 1 e 3 ) estiveram internados em leprosários durante algum tempo e só mais tarde foram reconhecidos como doentes de leishmaniose. Mesmo no caso no 2, em que as lesões se apresentavam localizadas, dentre as impressōes clínicas formuladas estava a de hanseníase, só esclarecida pelos exames de laboratório.

Ainda recentemente, Callot \& cols (5) descreveram um caso da forma difusa e relataram que a primeira impressão clínica foi de lepra: "R.G.R. - nous a été adressé en aout 1966 avec le diagnostic de lepra ... nombreux arguments plaidaient en faveur de cette etiologie ... A notre grande surprise toutes les recherches de bacilles de Hansen sont restées negatives..."

Para obviar os inconvenientes acima referidos, sem desvincular entretanto de sua semelhança do ponto de vista semiótico com a hanseniase, a que tal ênfase tem sido dada por quase todos os autores, propomos nova designaçăo - LEISHMANIOSE ANERGICA HANSENOIDE - como o fazemos no presente trabalho.

As denominações "difusa e generalizada" são também passiveis de crítica, de vez que em alguns casos as lesões podem ser localizadas, como ocorre em nossa observação no 2.

Revendo a literatura médica, verificamos que os casos registrados desta forma de leishmaniose, determinados pela Leishmania brasiliensis, não atingem a duas dezenas. 
Na região neotrópica, temos a considerar:

\section{a) No Brasil}

1 caso de Flaviano Silva (24), em 1944

1 caso de Guimarães (15), em 1951

1 caso de Portugal \& Marques (20), em 1960

1 caso de N. Guimarães (16), em 1963

1 caso de Teixeira \& $N$. Guimarães (28), em 1963

1 caso de Porto Marques (15), em 1965.

\section{b) Na Venezuela}

2 casos de Convit \& cols (8), em 1948

4 casos de Convit \& cols (9), em 1957

1 caso de Medina \& Romero (14), em 1959

\section{c) Em Honduras}

1 caso de Padilla \& Lainez (17), em 1968

\section{d) Nos Estados Unidos}

1 caso de Simpson, Mullins \& Stone (26), em 1968

\section{e) No México}

2 casos de Ramos Aguirre (21), em 1970

Assim sendo, temos um total de 17 casos apenas, o que atesta a raridade desta forma clinica de leishmaniose. É bem verdade que existem numerosos outros casos de "leishmaniose difusa ou disseminada" registrados na bibliografia médicas. São no entanto determinados pela Leishmania tropica, como os casos de Thompson \& Balfour, em 1910, no Sudão (in 15); as observações de Chakravarty \& Battacharyya (6), na India, as quais são contestadas ainda recentemente por Simpson \& cols. (27) ; um caso de Balzer \& cols. (19), em 1960, na Abissinia. Ou ainda os casos vistos por Haddida, na Algéria e Basset no Senegal (in 5) ; as observações de Schaller \& Serié (22), em 1963; o caso de Pages \& cols. (18) ou o caso já referido por Callot \& cols. (5), que em última análise não se enquadram plenamente na forma que ora descrevemos.

Recentemente, Bryceson (4) estudou 33 cassos na Abissinia, porém determinados pela $L$. tropica e não apresentando total- mente o comportamento da leishmaniose anérgica hansenóide, determinada pela $L$. brasitiensis.

De outro lado, é necessário não confundir esta forma clínica com as manifestações concomitantes ou póscalazar, que têm sido registradas em diversas partes do mundo, inclusive no Brasil; por exemplo, Magalhães, Fontenele \& Alcântara (12) descreveram um caso de calazar com manifestações cutâneas: "com lesões contemporâneas, representadas por nódulos e ulcerações na fronte, orelhas e membros inferiores" que se superpōem às descriçōes das lesōes da leishmaniose anérgica hansenóide.

Neste estudo crítico, não incluimos também diversos casos registrados, por não considerá-los verdadeiros. Assim o caso de Leon (11), no Equador, no qual o A. relata "mutilações auriculares extensas," ou os casos de Schambrom \& cols. (23), no Panamá, que na opiniāo de Guimarães "são casos típicos de espúndia".

Embora trabalhando em área que representa um grande foco de leishmaniose (Estado do Pará - Amazônia - Brasil), seja em sua forma cutânea, simulando por vezes o próprio "botão do oriente", ou cutâneomucosa (tipo espúndia), temos que considerar extremamente rara a forma anérgica hansenóide. Só admitimos como tal os casos que coincidem em seus aspectos clínicos, parasitológicos e imunológicos, como os já referidos nas observações acima.

Eis porque estatuimos alguns pré-requisitos para enquadrar um caso na forma "anérgica hansenóide":

1. Lesóes nodulares - uma das caractetísticas clínicas mais evidentes. Os nódulos geralmente são múltiplos, conglomerados, isolados ou em "placards" infiltrados, dai as denominações dadas por Silva (25) e Guimarāes (16). As lesões chegam a simular a forma polar lepromatosa da hanseníase, motivo das denominações dadas por diversos autores, já referidos.

Evidentemente 0 aspecto lepromatoso não pode ser afastado da descrição semiótica deste quadro clínico. 
2. Riqueza de leishmanias - seja nos cortes histológicos, seja nos "frottis", transformando as áreas lesionadas em "verciadeiras culturas de leishmanias".

3. Anergia - as reações à leishmanina (Reação de Montenegro), feitas em épocas diferentes e com antigenos de diversas procedência - sempre se apresentam negativas.

Bryceson (4) em suas observações refere ter encontrado 3 pacientes com reação positiva, o que nos parece estranho e a nosso ver invalidaria considerá-las como pertencentes à esta forma clínica. Além disso, esse mesmo A. admite as possibilidades de positivação da reação de Montenegro em pacientes curados (!) e aceita tal resultado como critério de cura. Há ainda um registro muito interessante no trabalho de Bryceson: pacientes anérgicos, que apresentaram positividade à reação de Montenegro após tratamento, voltaram a ser negativos - quando em fase de recidiva.

BITTENCOURT \& GUIMARÃES (3) em estudo clinico-patológico e imunológico de 3 pacientes desta forma de leishmaniose, registraram uma moderada inflitração linfoplasmocitária, cujos plasmócitos mostravam pirininofilia e material PAS positivo e gamaglobulina em seu citoplasma, pelo que admitiram que "a resposta imunocelular nesta doença modifica os conceitos primordiais de que representa uma forma anérgica "No entanto, a capacidade anergisante deve ser atribuida, em realidade, ao parasito, como se deduz das observações de Kerdel-Vegas (27), em dois voluntáríos.

4. Lesões em regra disseminadas - atingindo várias áreas do tegumento, donde as denominaçõões usadas por Silva (25), Mayer \& cols. (13) e Convit $\mathrm{K}$ cols. (8). E bem verdade que alguns casos têm sido referidos, nos quais as lesões se apresentam limitadas à determinadas áreas, como acontece com a nossa observação no 2.

5. Lesōes puramente cutâneas - esta forma anômala mostra tendência a fugir das mucosas. Sabemos que a leishmaniose americana apresenta marcado tropismo, no decurso de sua evolução, no sentido de atingir as mucosas, chegando por vezes a determinar mutilações extensas. Entretanto, os casos de leishmaniose anérgica hansenóide (L. A.H.) que observamos, um deles com um longo "follow-up" (desde 1944), não mostram a menor tendência a esse respeito. Neste caso (obs. $n$ o 1), até observamos um fato que reputamos primordial: as lesōes do nariz (face cutânea) se detiveram ao nivel das aberturas narinárias; as lesōes peri-orais não atingiram a semimucosa dos lábios; as lesões do penis só atingiram a face cutânea do prepúcio. No caso $n^{\circ} 3$, com lesōes tão extensas, não registramos o minimo comprometimento das mucosas.

Por este motivo, refutamos as observações de Barrientos (2), quando relata um caso de leishmaniose sob o nome de leishmaniose atípica muco-cutânea e pretende inclui-lo entre os casos de L.A.H.

Alguns autores têm referido ligeiro ataque à mucosa nasal, como o fizeram Portugal \& Porto Marques (20) mas acentuam: "a mucosa nasal pode ser levemente afetada, porém em continuidade com o processo cutâneo" fato que não observamos em nossos casos.

6. Resistência d̀ terapêutica - as observaçóes colhidas a respeito desta forma de leishmaniose demonstram cabalmente que os pacientes não se beneficiam com as diversas terapêticas instituidas. Assim, o caso de F. Silva (25) revisto em 1963 por Teixeira \& Guimarães (28), com uma evolução de 18 anos; submetido então a tratamento com Anfotericina B, as lesões regridiram parcialmente, para reaparecerem com a suspensāo da droga. O nosso caso no 1, com 26 anos de evolução, não se beneficiou jamais das diversas terapêuticas instituidas. Nosso caso no 3 , ainda virgem de qualquer medida terapêutica, apresentou resultados que poderiamos rotular de espetaculares com stibogluconato de sódio (ver fotos) porém as lesões começaram a reaparecer após 3 mêses de suspensão da droga obrigando-nos a novas séries para controlar a doença. 


\section{$S U M M A R Y$}

The A. presents several anomalous forms of tegumentar leishmaniasis, with particular attention to the diffuse cutaneous form, that he prefers to be referred as Hansenoid anergic leishmaniasis.

\section{REFERÊNCIAS BIBLIOGRAFICAS}

1 - BALZER, R.J. \& COLS. - (in 7)

2 - BARRIENTOS, L.P. - Mem. Inst. Oswaldo Cruz 46 (2): 415, 1948.

3 - BITTENCOURT, A.L. \& GUIMARÃES, N.A. - Imunopatologia da leishmaniose tegumentar difusa. Med. Cutanea 2 (4): $395,1968$.

4 - BRYCESON, A.D.M. - Diffuse cutaneous leishmaniasis in Ethiopia Trans. Royal Soc. Trop. Med. and Hyg. 64 (34) : $369,1970$.

5 - CALLOT, J.; KREMER, M.; BASSET, M.; MALEVILLE, J. \& BASSET, A. Leishmaniose cutaneus d'origine mediterranénne dépisteés en Alasca. Bull. Soc. Path Exot. 62 (1): 131, 190 9.

6 - CHAKRAVARTY, A. N. \& BATTACHERYYA, A.K. - Calcutta Med. Journ. 48: 227, 1951.

7 - CONVIT, J., REYES, O. \& KERDELVEGAS, F. - Disseminated anergic american leishmaniasis. Arch. Derm. 76 (2) : 213, 1957.

8 - CONVIT. J. \& LAPENTA, P. - Sobre um caso de leishmaniasis de forma cisseminada. Rev. Policl., Caracas 18: $153,1948$.

9 -- CONVIT, J. \& LAPENTA, P. - (in 13).

10 - KERDEL-VEGAS, F. -Leishmaniasis difusa experimental. Derm. Rev. Mex. (3) : 307, 1966

11 - LEON, L.C. - Leishmanias y Leishmaniasis. Ed. Univ. Equador, 1957.

12 - MAGALHÃES, V.B.; FONTENELLE, Z. \& ALCÂNTARA, L.G. - Sobre um caso de leishmaniose visceral com lesões cutâneas contemporâneas. Rev. Soc. Bras. Med. Trop. (8) : 54, 1969.

13 - MAYER, M., CONVIT, J. \& PIFANO, F. - Estudios experimentales com una cepa de $L$. brasiliensis proveniente de un caso de leishmaniasis tegumentaria disseminada de aspec- to lepromatoso. Arch. Venez. Med. Trop. Parasit. Med, 1: 2, 1949.

14 - MEDINA, R. \& ROMERO, J. - Estudio sobre la leishmaniose tegumentar en Venezuela. Derm. Ven. 1: 30, 1957.

15 - NERY GUIMARÃES, F. - Estado atual dos conhecimentos da "forma lepromatosa" da leishmaniose tegumentar (L.T.). Hospital 67 (1) : 57, 1965.

16 - NERY GUIMARÃES, F. - Trabalho apresentado à Acad. Nac. Med. Brasil, 1963.

17 - PADILLA, H.C. \& LAINEZ, N.H. Leishmaniasis cutánea disseminada - Revision del tema e informe del primer caso in Honduras. Med. Cutanea 3 (2) : 119, 1968.

18 - PAGÉS, F. \& COLS. - A case of pseudo tumoral cutaneous leishmaniasis. Bull. Soc. Franç. Derm. Syph. 71: 698, 1964

19 - PESSOA, S.B. - Arq. Hig. Saúde., Publ., S. Paulo 26 (87): 41, 1961..

20 - PORTUGAL, H. \& MARQUES, A.P. Leishmaniose tegumentar difusa. O Hospital, Rio 57 (5) : 813, 1960.

21 - RAMOS AGUIRRE, C. - Leishmaniasis en la Región Carbonífera de Coahuila. Reporte de dos casos dela forma anérgica difusa. Derm. Rev. Mex. XIV (1) : 39, 1970.

22 - SCHALLER, K.F. \& SERIÉ, C. Leishmaniose cutanèe "pseudo-lepromateuse". Z. Hant. v. Geschl Krank 35 (11) : 310, 1963.

23 - SCHAMBROM, E. \& COLS. - (in 15)

24 -- SILVA, D. -- Leishmaniose tegumentar queloidiana. An. Bras. Derm. Sifil. 33 (1): 3,1958 .

25 - SILVA, F. - Forma raríssima de leishmaniose tegumentar: leishmaniose ciérmica não ulcerada em nó- 
dulos e extensas placas infiltradas e hiperpigmentadas. 1 Resen. An. Bras. An. Soc. Derm. Sifil., 1: 97, 1945, Rio (separatum).

26 - SIMPSON, M. H.; MULLINS, J. F. \& STONE, O. J. - Disseminated anergic cutaneous leishmaniasis. An autochthonous case in Texas and the Mexican State of Tamaulipas and
Nuevo Leon. Arch. Derm. 97 (3) : 301, 1968.

27 - SIMPSON, M.H.; MULLINS, J.F. \& STONE, O.J. - (in 26) .

28 - TEIXEIRA, R. \& GUIMARAES, N. Anfotericina B na leishmaniose tegumentar americana. Rev. Ass. Med. Bras. $9(7-8): 230,1963$. 


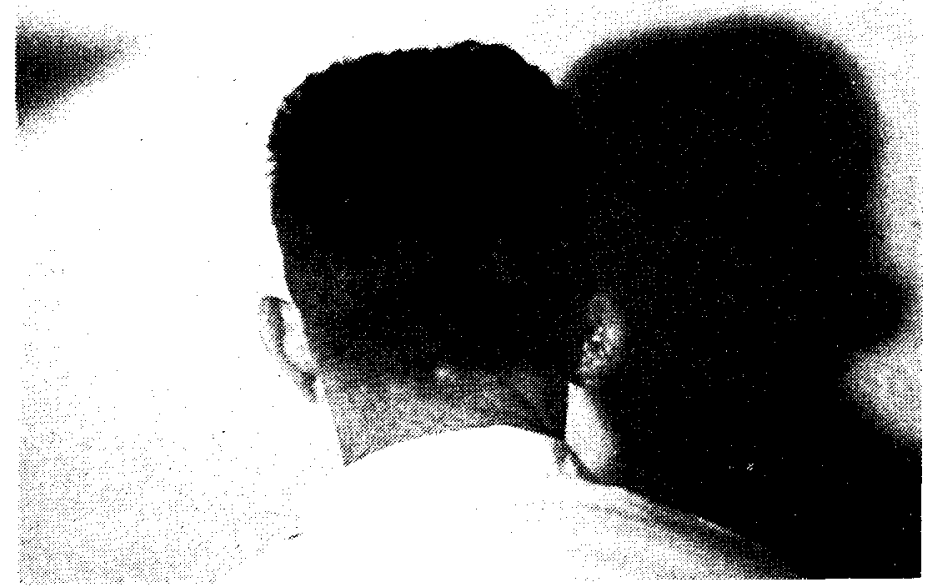

Fig. 1 - Lesão nodular ulcerada

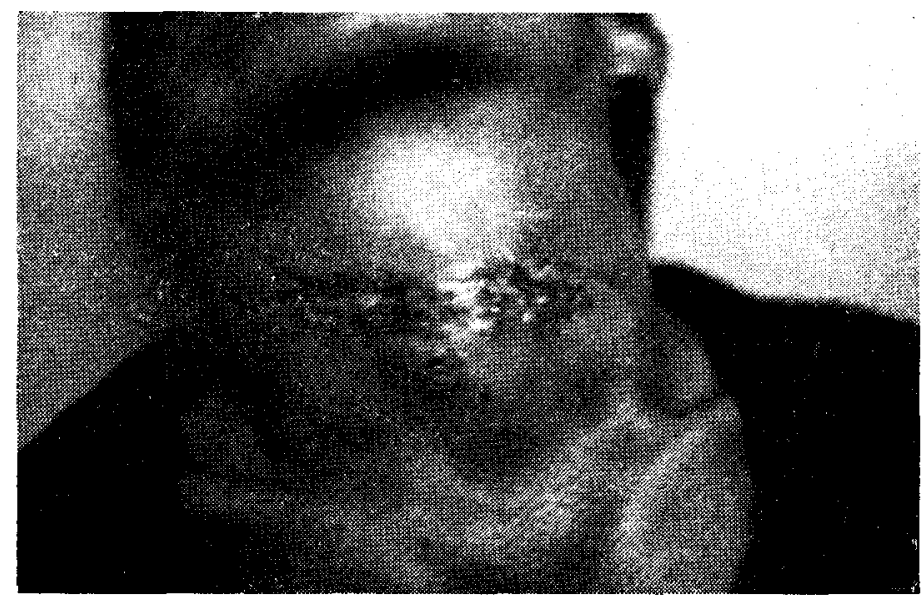

Fig. 2 - Tipo gomo-ulcerado, lembrando escrofuioderma. 


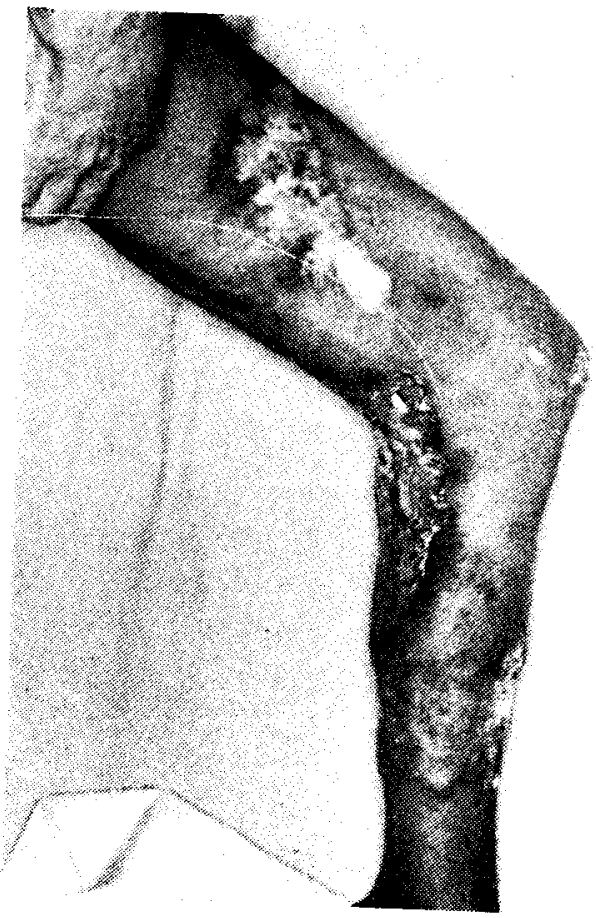

Fig. 3 - 'Tipo gomoso-ulcerado, com lesöes extensas.

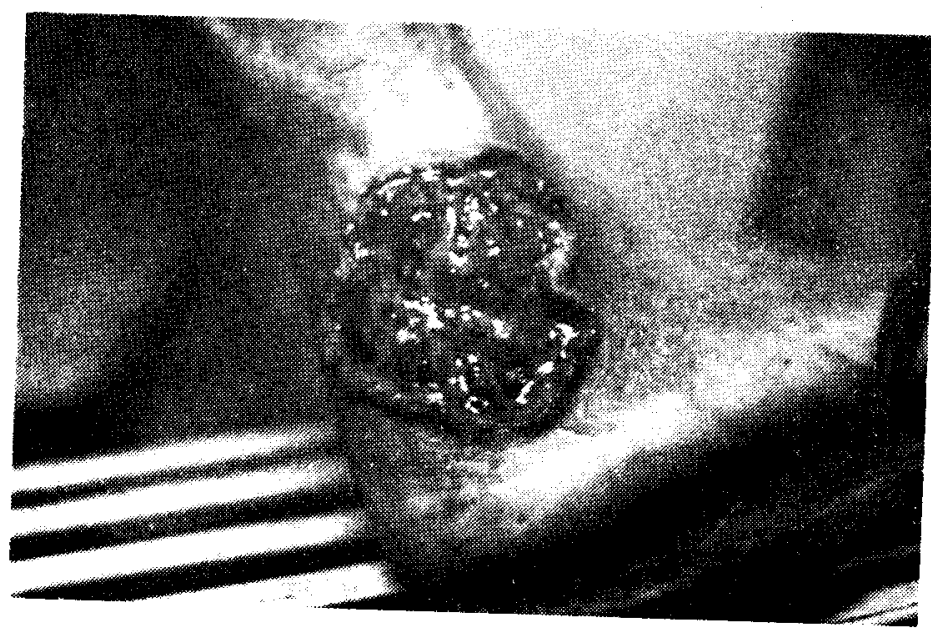

Fig. 4 - Úlcera leishmaniótica lembrando úlcera tropical por associação fusoespirilar. 


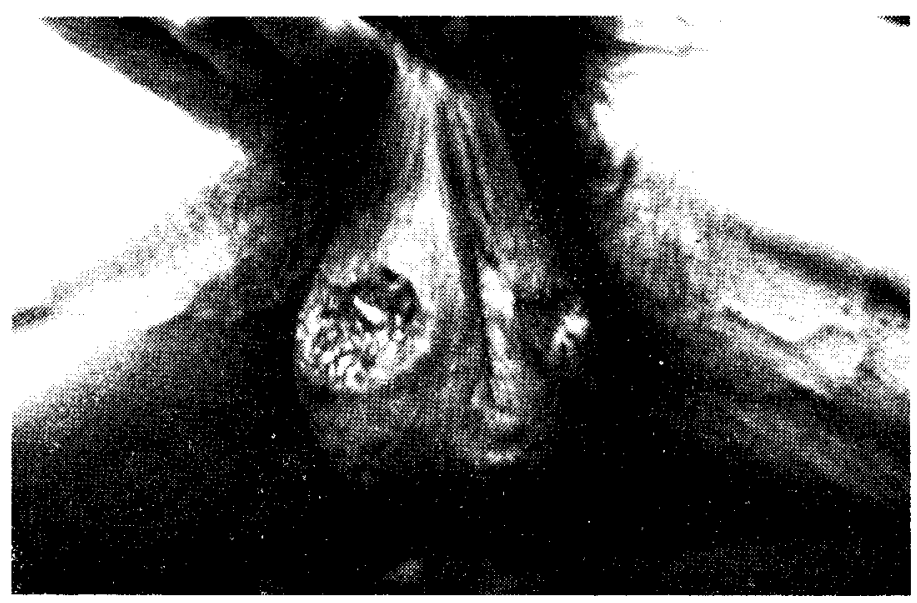

Fig. 5 - Lesão ulcerada na bolsa escrotal.

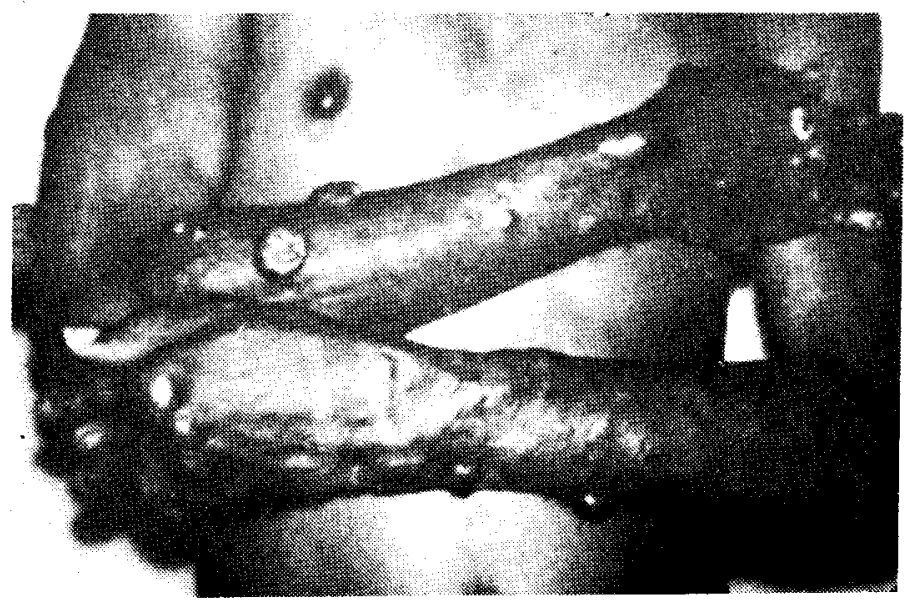

Fig. 6 - Leishmaniose anergica hansenoide. Lesóes nodulares disseminadas. (R. M. - doente há 26 anos). 


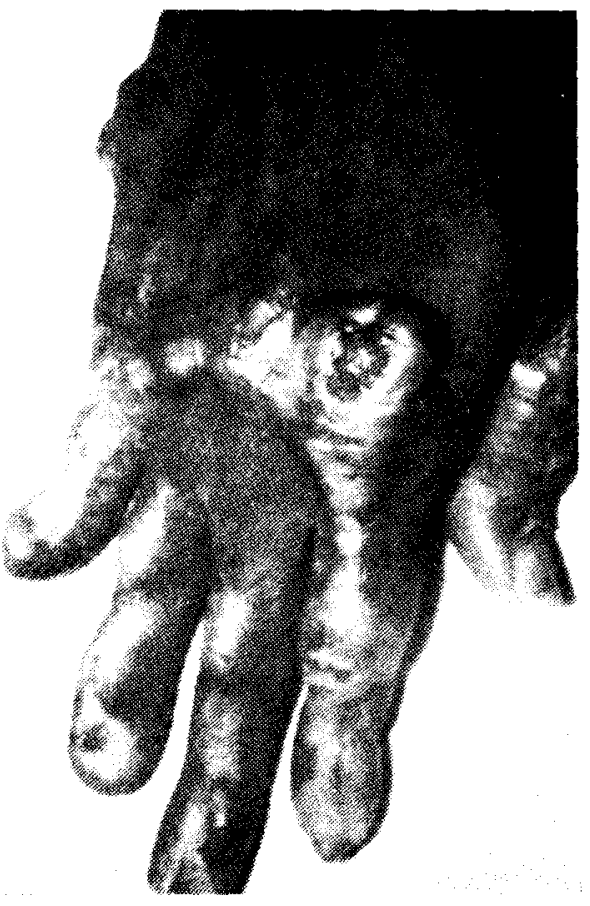

Fig. 7 - Leishmaniose anérgica hansenoide - R.M. Lesões ósseas.

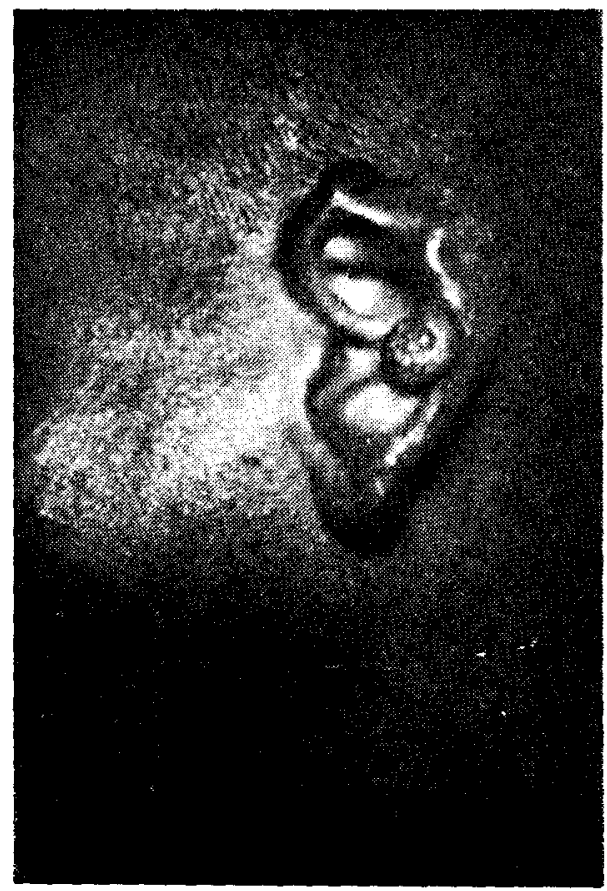

Fig. 8 - Leishmaniose anérgica hansenólde. R.M. Lesôes nodulares, com infiltração.

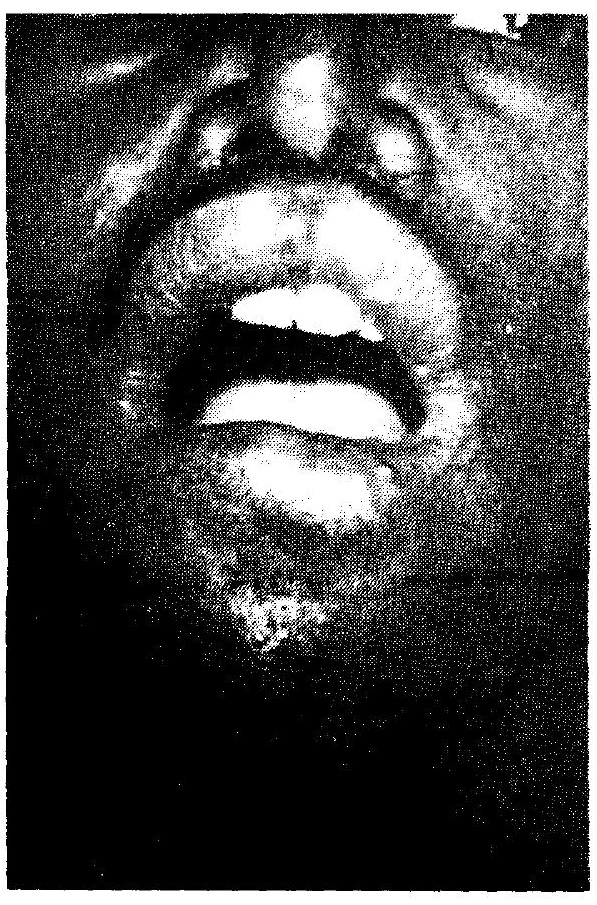




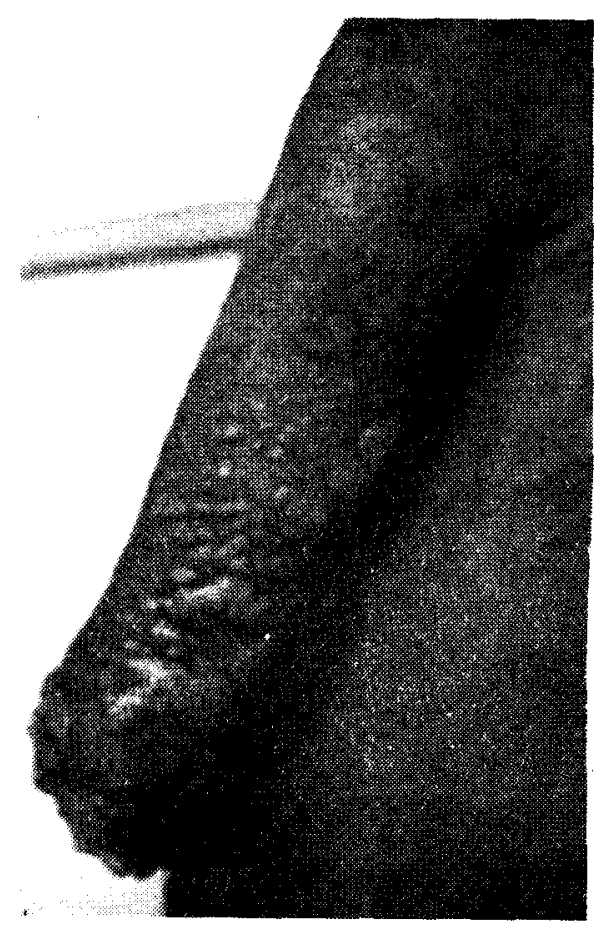

Fig. 12 - Leishmantose arérgica hansenóide. J.M.M.O. Lesōes ncdulares disseminadas, lembrando hanceniase.

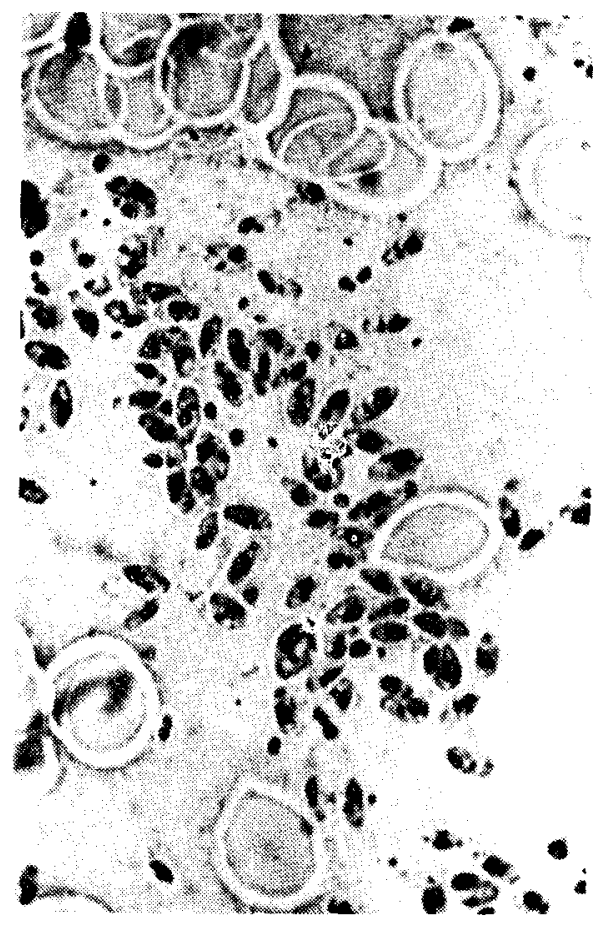

Fig. 14 - Riqueza de leishmanias nos esfregaccs. Típico da leishmaniose anérgica hansenóide. Notar o aspecto de "charuto" dos parasitos.

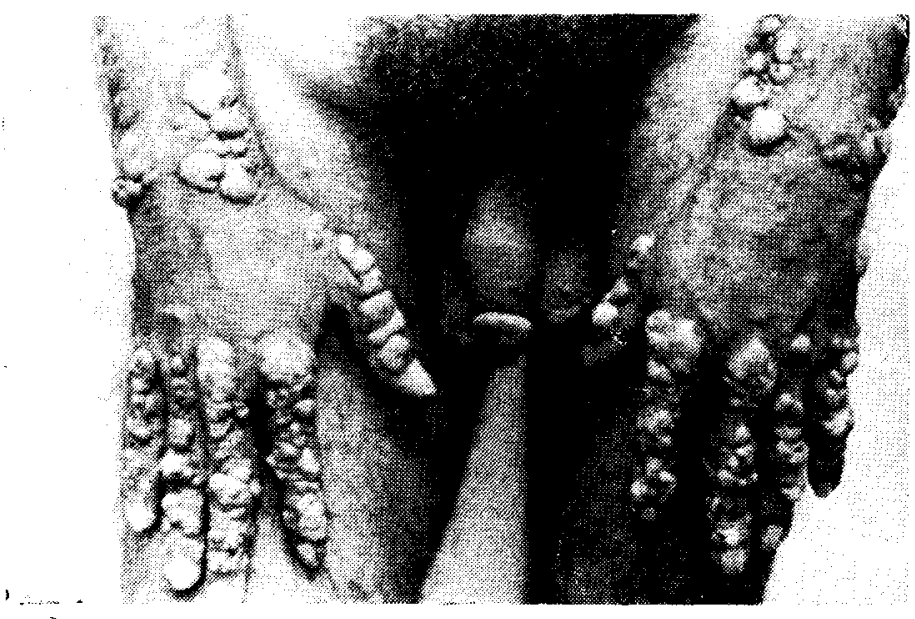

Ftg. 13 - Leishmanlose anérgica hansenólde. J.M.M.O. Extensas lesóes nodulares, tnelusive na bolsa escrotal. 